www.nature.com/hr

\title{
Prediction of pregnancy-induced hypertension by a shift of blood pressure class according to the JSH 2009 guidelines
}

\author{
Seung Chik Jwa ${ }^{1,2}$, Naoko Arata $^{3}$, Naoko Sakamoto ${ }^{2}$, Noriyoshi Watanabe ${ }^{1}$, Hiroaki Aoki ${ }^{1}$, Asako Kurauchi-Mito ${ }^{3}$, \\ Qiu Dongmei ${ }^{2}$, Yukihiro Ohya ${ }^{4}$, Atsuhiro Ichihara ${ }^{5,6}$ and Michihiro Kitagawa ${ }^{1,6}$
}

Elevated blood pressure (BP) at early or mid pregnancy is a known risk factor for pregnancy-induced hypertension (PIH). However, the association between BP changes during the first half of pregnancy and subsequent PIH development is unknown. We used changes in maternal BP between 16 and 20 weeks of gestation to evaluate the risk of PIH. A total of 976 pregnant women with BP estimations recorded before 16 weeks and at 20 weeks of gestation participated in this study. BPs were classified by the Japanese Society of Hypertension 2009 Hypertension Treatment Guidelines (JSH 2009). There was a significant trend for future PIH in women whose JSH 2009 BP class increased between 16 and 20 weeks of gestation, and the risk of PIH was highest among women whose BP was Class IV Hypertension (systolic BP $\geqslant 140 \mathrm{~mm} \mathrm{Hg}$ and/or diastolic $B P \geqslant 90 \mathrm{~mm} \mathrm{Hg}$ ). The risk of PIH increased in women whose BPs shifted from Classes I Optimal (systolic BP $<120 \mathrm{~mm} \mathrm{Hg}$ and diastolic BP $<80 \mathrm{~mm} \mathrm{Hg}$ ) and II Normal (systolic BP $120-129 \mathrm{~mm} \mathrm{Hg}$ and/or diastolic BP $80-84 \mathrm{~mm} \mathrm{Hg}$ ) before 16 weeks to Class III High-Normal (systolic BP $130-139 \mathrm{~mm} \mathrm{Hg}$ and/or diastolic BP $85-89 \mathrm{~mm} \mathrm{Hg}$ ) at 20 weeks of gestation. These shifts in BP class were significantly correlated with the risk of PIH after adjustments for variables ( $\boldsymbol{P}$-value for trend $<0.05$ ). Within JSH 2009 Classes I, II and III, a shift in BP from a low to a high class between 16 and 20 weeks of gestation predicts the subsequent development of PIH.

Hypertension Research (2011) 34, 1203-1208; doi:10.1038/hr.2011.107; published online 28 July 2011

Keywords: blood pressure; prediction; pregnancy-induced hypertension; risk factor

\section{INTRODUCTION}

Pregnancy-induced hypertension (PIH) refers to high blood pressure (BP) during pregnancy. PIH affects $3-10 \%$ of all pregnancies ${ }^{1-3}$ and is associated with high levels of maternal, fetal, and neonatal morbidity and mortality. ${ }^{1,4,5}$ Furthermore, the long-term prognosis of women with a history of PIH includes increased risks of cerebrovascular disease, ischemic heart disease and renal disease. ${ }^{6-12}$ These data indicate that the early identification, and subsequent monitoring and management of PIH are critical for maternal and fetal well-being.

In normotensive women, $\mathrm{BP}$ in early pregnancy decreases up to 20 weeks of gestation, and gradually increases to normal or higher than pre-pregnancy levels before delivery. ${ }^{13,14}$ A diagnosis of PIH includes a $\mathrm{BP}>140 / 90 \mathrm{~mm} \mathrm{Hg}$ in the late second or third trimester. Previous studies described successful screening for PIH development following a single estimation of maternal BP. However, the false positive rate and sensitivity of these studies varied widely, from 7 to $52 \%$ and 8 to
$93 \%,{ }^{15-19}$ respectively, indicating that this method is not sufficient for effective $\mathrm{PIH}$ prediction. In contrast, systematic monitoring of changes in BP during the early to mid stages of pregnancy may predict the development of PIH more exactly. Systematic sampling with 48-h ambulatory BP monitoring indicated that PIH was associated with a stable BP in the first half of gestation and a greater increase to delivery than in healthy pregnancies. ${ }^{20}$ In addition, the development of PIH in women with low education levels was related to the absence of a significant fall in diastolic BP at mid pregnancy compared with healthy pregnancies in women with higher education. ${ }^{21}$ These data indicate that information describing the changes in BP during early to mid pregnancy may be more predictive of subsequent $\mathrm{PIH}$ development than data recorded at a single measurement.

In the present study, we examined whether BP changes from early to mid gestational age are capable of predicting the development of PIH. BP was classified according to the JSH 2009 for easy clinical use. ${ }^{22}$

\footnotetext{
${ }^{1}$ Department of Maternal-Fetal and Neonatal Medicine, National Center for Child Health and Development, Tokyo, Japan; ${ }^{2}$ Department of Social Medicine, National Research Institute for Child Health and Development, National Center for Child Health and Development, Tokyo, Japan; ${ }^{3}$ Department of Women's Health, National Center for Child Health and Development, Tokyo, Japan; ${ }^{4}$ Department of Medical Specialties, National Center for Child Health and Development, Tokyo, Japan and ${ }^{5}$ Department of Medicine II, Institute of Endocrinology and Hypertension, Tokyo Women's Medical University, Tokyo, Japan

${ }^{6}$ These authors contributed equally to this paper

Correspondence: Professor A Ichihara, Department of Medicine II, Institute of Endocrinology and Hypertension, Tokyo Women's Medical University, Tokyo 162-8666, Japan. E-mail: atzichi@endm.twmu.ac.jp
}

Received 17 March 2011; revised 1 May 2011; accepted 9 May 2011; published online 28 July 2011 


\section{METHODS}

\section{Study population and design}

Our investigations are part of the Tokyo-Children's Health, Illness and Development Study. This is a unicenter, longitudinal, prospective observational birth cohort study conducted at the National Center for Child Health and Development (Tokyo, Japan). The aims of this cohort study are: (1) to investigate the influence of maternal weight gain and nutrition during pregnancy on the birth weight, growth and development of infants, (2) to identify the influence of maternal environment on the development of childhood allergies, (3) to study the influence of the prenatal and perinatal environment (fetus) on the psychological and psychiatric development of the infant, (4) to study the influence of parental attitude and knowledge about child rearing on the parentchild relationship and the development of children and (5) to determine the feasibility of using an electronic medical record system to conduct a birth cohort study. The participants in the Tokyo-Children's Health, Illness and Development Study were recruited at their first antenatal visit, before 16 weeks of gestation, from October 2003 to December 2005. Institutional review boards at the National Center for Child Health and Development approved our investigations.

We used the cohort data to analyze the relationship between BP changes during the first half of pregnancy and the onset of PIH. Our inclusion criteria accepted only participants with BP estimations recorded before 16 weeks and at 20 weeks of gestation (18-22 weeks of gestation), and who delivered at our institution after 22 weeks. Subjects with multiple gestations, pre-existing hypertension and pre-existing proteinuria were excluded. A total of 1019 women were initially included, from which 43 cases were excluded because of mismatched selection criteria and loss of information; therefore, data from 976 women were used in our analyses (Figure 1).

\section{Measurement and classification of BP}

After 5 min rest, BP was measured in the sitting position with the right arm held at heart level, using an automated sphygmomanometer (Omron BP203RVIII oscillometer; Nippon Colin, Tokyo, Japan). BP monitoring was performed at two time points: before 16 weeks and between 18 and 22 weeks of gestation. If BP was measured on several occasions before 16 weeks, the average systolic and diastolic values were evaluated.

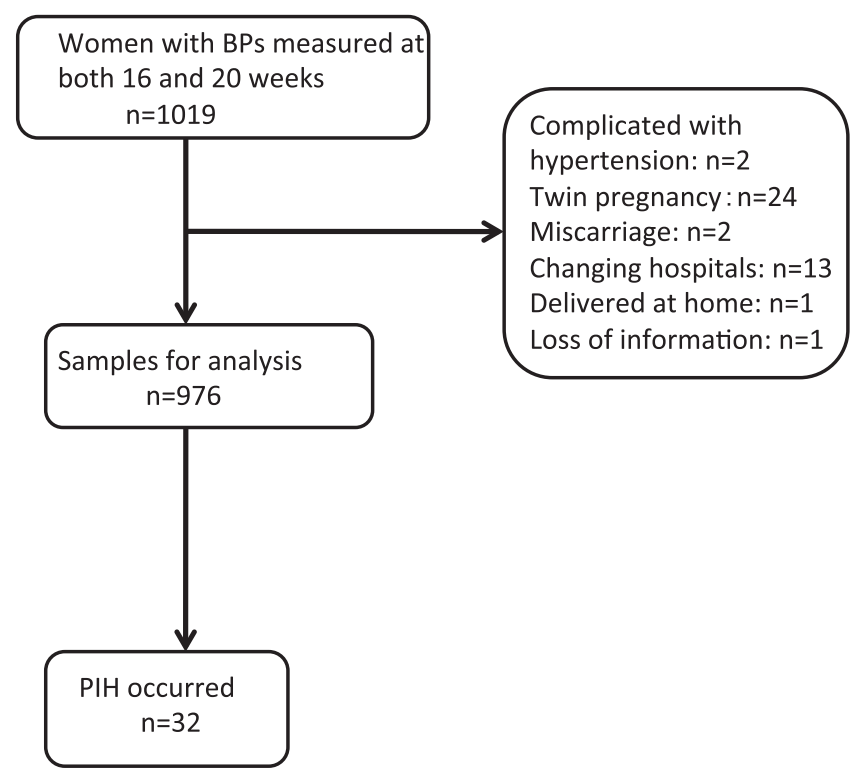

Figure 1 Flow diagram showing sample selection for our analyses. A total of 1019 pregnant women with BP estimations recorded before 16 weeks and at 20 weeks of gestation (18-22 weeks of gestation) were initially included in the study; 976 subjects were enrolled because of mismatched selection criteria and loss of information. Pregnancy-induced hypertension occurred in 32 women. BP, blood pressure; $\mathrm{PIH}$, pregnancy-induced hypertension.
BPs were stratified into four groups based on Japanese Society of Hypertension 2009 Hypertension Treatment Guidelines (JSH 2009): ${ }^{22}$ Class I (Optimal), systolic $\mathrm{BP}<120 \mathrm{~mm} \mathrm{Hg}$ and diastolic $\mathrm{BP}<80 \mathrm{~mm} \mathrm{Hg}$; Class II (Normal), systolic BP $120-129 \mathrm{~mm} \mathrm{Hg}$ and/or diastolic BP $80-84 \mathrm{~mm} \mathrm{Hg}$; Class III (High-Normal), systolic BP $130-139 \mathrm{~mm} \mathrm{Hg}$ and/or diastolic BP $85-89 \mathrm{~mm} \mathrm{Hg}$; Class IV (Hypertension), systolic $\mathrm{BP} \geqslant 140$ or diastolic $\mathrm{BP} \geqslant 90 \mathrm{~mm} \mathrm{Hg}$

\section{Definition of PIH}

PIH was defined according to Guideline 2009 for care and treatment of hypertension in pregnancy by the Japan Society of the Study of Hypertension in Pregnancy ${ }^{23}$ as: 'hypertension with or without proteinuria occurring after 20 weeks of gestation but resolving by twelve weeks postpartum.. We excluded superimposed PIH, defined as: 'pre-existing hypertension with new onset of proteinuria after 20 weeks of gestation, or pre-existing proteinuria with new onset of hypertension.'

\section{Other baseline data}

Information describing sociodemographic, medical and behavioral data, past medical history, previous pregnancy complications, family history of hypertension or diabetes mellitus, smoking, education, family income and delivery were collected from the database of the cohort study.

\section{Statistical analysis}

Student's $t$-test and Mann-Whitney $U$-test were performed for analysis between two continuous variables, and $\chi^{2}$-test or Fisher's exact test was used for discrete variables. The influence of BP class on the development of PIH was assessed by multiple logistic regression analysis. The probability of PIH occurrence was determined from the shifts in BP classes between 16 and 20 weeks of gestation and evaluated with odds ratios and $P$-values. All analyses were performed with the SPSS software (version 18 for Windows; SPSS, Chicago, IL, USA). $P<0.05$ was considered statistically significant.

\section{RESULTS}

\section{Patient characteristics}

Baseline patient characteristics are shown in Table 1. In 976 participants, 32 of the index pregnancies $(3.3 \%)$ were eventually complicated with PIH. There were no significant differences in the gestational ages of participants at the times of BP monitoring. Maternal age, maternal pre-existing diabetes mellitus and previous history of $\mathrm{PIH}$ were significantly different between the PIH and non-PIH groups. Other variables (pre-pregnancy body mass index, rate of nulliparity, maternal pre-existing renal disease, previous pregnancy history of fetal growth restriction and placental abruption, rate of smoking, educational levels, distribution of family income, family history of diabetes mellitus, hypertension, ischemic heart disease, cerebrovascular stroke, chronic renal disease) were similar.

\section{Pregnancy and delivery outcomes}

Pregnancy and delivery outcomes in the non-PIH and PIH groups are shown in Table 2. The gestational age of delivery was significantly lower and the rate of preterm delivery was higher in the PIH group compared with non-PIH subjects. The rate of normal vaginal delivery was significantly lower and the rate of instrumental delivery was higher in the PIH group. The frequency of cesarean section (both planned and emergency) was similar between both groups. Placental weight and neonatal birth weight were significantly lower in the PIH group, and the number of neonates with an Apgar score of $\leqq 7$ at 5 min was significantly higher.

\section{Analysis for PIH risk based on BP classification}

Table 3 shows the crude and adjusted odds ratios, and confidence intervals of PIH occurrence according to class of BP (based on JSH 
Table 1 Baseline characteristics of the PIH and non-PIH groups

\begin{tabular}{|c|c|c|c|c|c|}
\hline Characteristics & & $A / l(\mathrm{n}=976)$ & PIH group $(\mathrm{n}=32)$ & non-PIH group $(\mathrm{n}=944)$ & P-value \\
\hline Maternal age (years) & mean (s.d.) & $33.6(4.1)$ & $35.3(4.5)$ & $33.5(4.1)$ & 0.028 \\
\hline Maternal height (cm) & mean (s.d.) & $159.4(5.1)$ & $158.7(5.5)$ & $159.4(5.1)$ & NS \\
\hline Maternal pre-pregnancy body weight (kg) & mean (s.d.) & $51.3(6.5)$ & $52.0(8.0)$ & $51.3(6.5)$ & NS \\
\hline Pre-pregnancy BMI $\left(\mathrm{kg} \mathrm{m}^{-2}\right)$ & mean (s.d.) & $20.2(2.4)$ & $20.6(2.4)$ & $20.2(2.4)$ & NS \\
\hline \multicolumn{6}{|l|}{ Parity } \\
\hline 0 & $n(\%)$ & $489(50.1)$ & $19(59.4)$ & $470(49.8)$ & NS \\
\hline$\geqq 1$ & $n(\%)$ & $487(49.9)$ & $13(40.6)$ & $474(50.2)$ & \\
\hline Mean gestational age before 16 weeks blood pressure & mean (s.d.) & $14.3(1.0)$ & $14.3(1.0)$ & $14.2(1.1)$ & NS \\
\hline Mean gestational age at 20 weeks blood pressure & mean (s.d.) & $20.0(1.2)$ & $20.0(1.2)$ & $20.1(1.2)$ & NS \\
\hline \multicolumn{6}{|l|}{ Maternal pre-pregnancy complications } \\
\hline Diabetes mellitus & $n(\%)$ & $6(0.6)$ & $2(6.3)$ & $4(0.4)$ & 0.014 \\
\hline Renal disease & $n(\%)$ & $2(0.2)$ & $1(3.1)$ & $1(0.1)$ & NS \\
\hline \multicolumn{6}{|l|}{ Previous pregnancy complications } \\
\hline $\mathrm{PIH}$ & $n(\%)$ & $12(1.2)$ & $4(12.5)$ & $8(0.8)$ & $<0.001$ \\
\hline Fetal growth restriction & $n(\%)$ & $5(0.5)$ & $1(3.1)$ & $4(0.4)$ & NS \\
\hline Placental abruption & $n(\%)$ & $2(0.2)$ & $1(3.1)$ & $1(0.1)$ & NS \\
\hline \multicolumn{6}{|l|}{ Smoking } \\
\hline Never or former & $n(\%)$ & 944 (96.9) & $31(96.9)$ & $913(96.9)$ & NS \\
\hline Current & $n(\%)$ & $30(3.1)$ & $1(3.1)$ & $29(3.1)$ & \\
\hline Education (high school or less) & $n(\%)$ & $94(10.1)$ & $4(12.9)$ & $90(10.0)$ & NS \\
\hline \multicolumn{6}{|l|}{ Income (per year) } \\
\hline$<4$ million yen & $n(\%)$ & $55(6.2)$ & $3(10.0)$ & $52(6.0)$ & NS \\
\hline$<6$ million yen & $n(\%)$ & $202(22.6)$ & $6(20.0)$ & $196(22.7)$ & \\
\hline$<8$ million yen & $n(\%)$ & $198(22.2)$ & $9(30.0)$ & $189(21.9)$ & \\
\hline$<10$ million yen & $n(\%)$ & $192(21.5)$ & $4(13.3)$ & $188(21.8)$ & \\
\hline over 10 million yen & $n(\%)$ & $246(27.5)$ & $8(26.7)$ & $238(27.6)$ & \\
\hline \multicolumn{6}{|l|}{ Family History } \\
\hline Diabetes mellitus & $n(\%)$ & $73(7.5)$ & $0(0.0)$ & $73(7.7)$ & NS \\
\hline Hypertension & $n(\%)$ & $72(7.4)$ & $4(12.5)$ & $68(7.2)$ & NS \\
\hline Ischemic heart disease & $n(\%)$ & $38(3.9)$ & $1(3.1)$ & $37(3.9)$ & NS \\
\hline Cerebrovascular stroke & $n(\%)$ & $18(1.8)$ & $0(0.0)$ & $18(1.9)$ & NS \\
\hline Chronic renal disease & $n(\%)$ & $8(0.8)$ & $0(0.0)$ & $8(0.8)$ & NS \\
\hline
\end{tabular}

Abbreviations: BMI, body mass index; NS, not significant; PIH, pregnancy-induced hypertension; s.d., standard deviation.

2009) before 16 weeks of gestation. Although the risk of PIH was significantly higher in Class III and IV subjects without adjustments for any variables, these risks became insignificant after variables were accounted for. However, the trend of PIH occurrence was statistically significant, regardless of any adjustments.

Table 4 demonstrates the crude and adjusted odds ratios of PIH occurrence based on BPs at 20 weeks of gestation. The risk of PIH was significantly greater in all Class II, III and IV subjects with or without adjustments for variables.

BP class shift from 16 weeks to 20 weeks gestation and the risk of PIH occurrence

Table 5 shows the shifts in BP classes between 16 and 20 weeks of gestation, and their associations with $\mathrm{PIH}$ occurrence. Odds ratios and $95 \%$ confidence intervals were calculated based on each BP class before 16 weeks of gestation. Women with Class IV (Hypertension) BPs before 16 or at 20 weeks of gestation were excluded, because they were already considered high risk for PIH as indicated in Tables 3 and 4 .

The subjects with BPs that did not shift class between 16 and 20 weeks of gestation were referred to as baseline. The risk of PIH occurrence was significantly higher in subjects whose BP shifted from Class I at 16 weeks to Class III at 20 weeks of gestation. The risk of PIH occurrence was not statistically significant in subjects whose BP shifted from Class I to II at 16 and 20 weeks of gestation, respectively; however, the trend for PIH risk was significant ( $P$-value for trend $<0.05)$ and remained significant even after adjustments for all variables. When comparing two groups, one in which the BP class elevated to Class II or III at 20 weeks gestation and the other in which the BP class did not change, the sensitivity, false positive rate and positive predictive value of BP class elevation between 16 and 20 weeks of gestation were $33.3,10.8$ and $7.4 \%$, respectively. The risk of PIH occurrence was significantly higher in subjects whose BP shifted from Class II at 16 weeks to Class III at 20 weeks of gestation, although this 
Table 2 Pregnancy and delivery outcomes of the PIH and non-PIH groups

\begin{tabular}{|c|c|c|c|c|c|}
\hline & & $A / l(n=976)$ & PIH group $(\mathrm{n}=32)$ & non- $P I H$ group $(n=944)$ & P-value \\
\hline Gestational age (weeks) & mean (s.d.) & $39.1(1.8)$ & $37.8(1.9)$ & $39.1(1.7)$ & $<0.001$ \\
\hline$<37$ & $n(\%)$ & $59(6.0)$ & $11(34.4)$ & $48(5.1)$ & $<0.001$ \\
\hline Stillbirth & $n(\%)$ & $2(0.2)$ & $1(3.1)$ & $1(0.1)$ & NS \\
\hline \multicolumn{6}{|l|}{ Delivery mode } \\
\hline Total Cesarean section & $n(\%)$ & $208(21.3)$ & $10(31.3)$ & $198(21.0)$ & NS \\
\hline Planned cesarean section & $n(\%)$ & $124(12.7)$ & $6(18.8)$ & $118(12.5)$ & NS \\
\hline Emergency cesarean section & $n(\%)$ & $84(8.6)$ & $4(12.5)$ & $80(8.5)$ & NS \\
\hline Placental weight (g) & mean (s.d.) & $558.4(104.6)$ & $513.0(100.9)$ & $560.0(104.4)$ & 0.022 \\
\hline Birth weight (g) & mean (s.d.) & $3003.6(421.8)$ & $2618.7(538.7)$ & $3016.6(411.3)$ & $<0.001$ \\
\hline Head circumference $(\mathrm{cm})$ & mean (s.d.) & $33.1(1.4)$ & $32.4(1.7)$ & $33.2(1.4)$ & 0.007 \\
\hline
\end{tabular}

Abbreviations: NS, not significant; PIH, pregnancy-induced hypertension; s.d., standard deviation.

Table 3 Unadjusted and multivariable adjusted ORs (95\% Cls) of PIH occurrence classified by blood pressure before 16 weeks of gestation

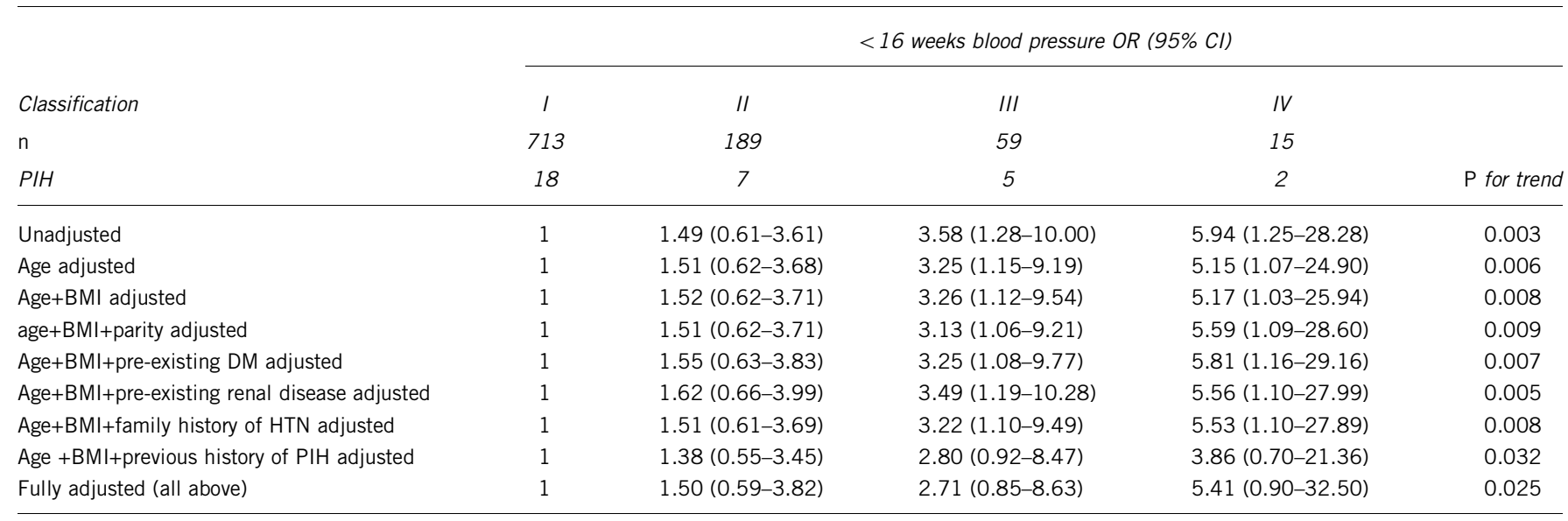

Abbreviations: BMI, body mass index; Cl, confidence interval; DM, diabetes mellitus; HTN, hypertension; OR, odds ratio; PIH, pregnancy-induced hypertension.

Table 4 Unadjusted and multivariable adjusted ORs (95\% Cls) of PIH occurrence classified by blood pressure at 20 weeks of gestation

\begin{tabular}{|c|c|c|c|c|c|}
\hline \multirow[b]{2}{*}{ Classification } & \multicolumn{5}{|c|}{20 weeks blood pressure OR (95\% Cl) } \\
\hline & 1 & II & III & IV & \\
\hline $\mathrm{n}$ & 782 & 143 & 44 & 7 & \\
\hline$P I H$ & 14 & 7 & 9 & 2 & $\mathrm{P}$ for trend \\
\hline Unadjusted & 1 & $2.82(1.12-7.12)$ & $14.11(5.72-34.81)$ & $21.94(3.92-122.90)$ & $<0.001$ \\
\hline Age adjusted & 1 & $2.78(1.10-7.05)$ & $13.57(5.45-33.78)$ & $19.10(3.32-109.76)$ & $<0.001$ \\
\hline Age+BMI adjusted & 1 & $2.89(1.14-7.36)$ & $14.84(5.76-38.37)$ & $21.02(3.57-123.61)$ & $<0.001$ \\
\hline Age+BMI+parity adjusted & 1 & $2.84(1.11-7.24)$ & $14.66(5.68-37.84)$ & $19.34(3.23-115.71)$ & $<0.001$ \\
\hline Age+BMI+pre-existing DM adjusted & 1 & $2.94(1.15-7.50)$ & $13.94(5.29-36.73)$ & $22.76(3.85-134.50)$ & $<0.001$ \\
\hline Age $+\mathrm{BMI}+$ pre-existing renal disease adjusted & 1 & $2.95(1.16-7.54)$ & $13.94(5.31-36.62)$ & $21.63(3.66-127.85)$ & $<0.001$ \\
\hline Age+BMI+family history of HTN adjusted & 1 & $2.88(1.13-7.34)$ & $14.40(5.53-37.46)$ & $21.58(3.66-127.38)$ & $<0.001$ \\
\hline Age +BMI+previous history of $\mathrm{PIH}$ & 1 & $2.98(1.15-7.76)$ & $13.96(5.22-37.31)$ & $23.50(3.95-140.02)$ & $<0.001$ \\
\hline Fully adjusted (all above) & 1 & $3.01(1.14-7.98)$ & $11.72(4.13-33.26)$ & $24.14(3.81-152.99)$ & $<0.001$ \\
\hline
\end{tabular}

Abbreviations: BMI, body mass index; Cl, confidence interval; DM, diabetes mellitus; HTN, hypertension; OR, odds ratio; PIH, pregnancy-induced hypertension. 
Table 5 Blood pressure class shift from 16 weeks to 20 weeks of gestation and the risk of PIH occurrence

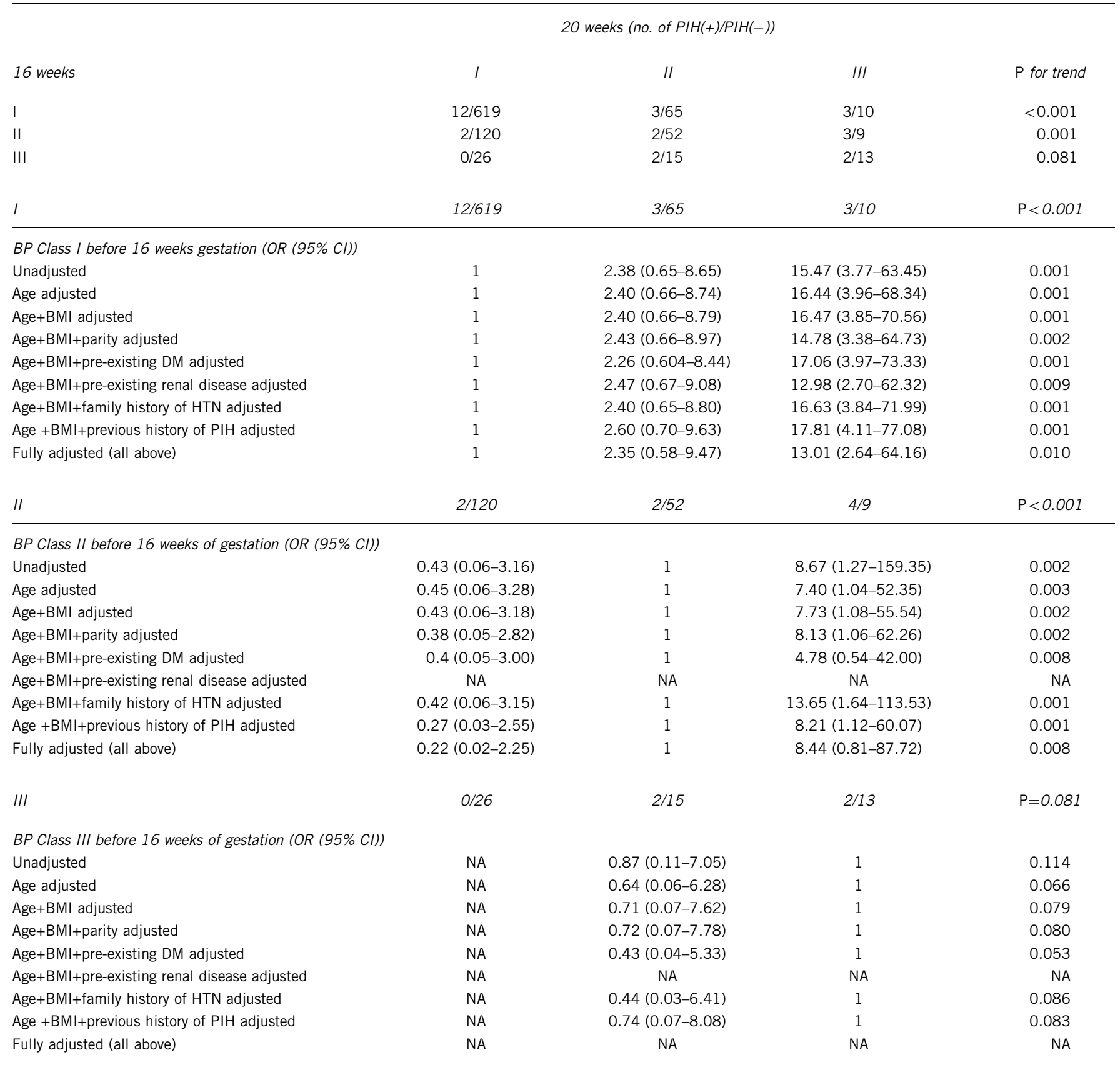

Abbreviations: BMI, body mass index; BP, blood pressure; Cl, confidence interval; DM, diabetes mellitus; HTN, hypertension; NA, not available; OR, odds ratio; PIH, pregnancy-induced hypertension.

risk became insignificant after adjustment for pre-existing diabetes mellitus. The risk of PIH occurrence was not statistically significant in subjects whose BP shifted from Class II at 16 weeks to Class I at 20 weeks of gestation. However, the trend for PIH risk was significant $(P<0.05)$ and remained significant even after adjustments for all variables. When comparing two groups, one in which the BP class elevated to Class III at 20 weeks gestation and the other in which the BP class did not change or decreased to Class I, the sensitivity, false positive rate and positive predictive value of BP class elevation between 16 and 20 weeks of gestation were 50.0, 5.0 and 30.8\%, respectively. Subjects whose BP shifted from Class III at 16 weeks to
Classes I and II at 20 weeks of gestation were not associated with a significant risk reduction of PIH (Table 5).

\section{DISCUSSION}

In this study, we classified BP in pregnant women according to JSH 2009. Our results suggested that the risk of PIH could be predicted from BP class shifts between 16 and 20 weeks of gestation. The elevation of BP over the course of pregnancy was associated with a significant risk for future development of PIH even among women with Class I (Optimal) and II (Normal) BPs before 16 weeks of gestation, who are normally recognized as low risk for PIH. 
In a previous study, Hermida et al. ${ }^{20}$ compared the time course of $\mathrm{BP}$ changes during pregnancy in normotensive and $\mathrm{PIH}$ women. The normotensive women had a steady decrease in BP toward 20 weeks; this was absent in patients with gestational hypertension and preeclampsia. Silva et al. ${ }^{21}$ investigated the effect of maternal education levels on BP alterations in pregnancy. They found the absence of a mid-pregnancy fall in diastolic BP in low educational groups with a high occurrence of PIH. However, both studies failed to analyze the direct association between changes in BP during pregnancy and the risk of PIH. In this study, we clearly demonstrated a significant association between an increased BP during the first half of pregnancy and the risk of PIH.

Our results are in accordance with those previously reported, which identified normal and high-normal BPs at early and mid pregnancy as predictors of subsequent PIH development. ${ }^{5,23}$ We used the JSH 2009 classification to show a significant trend for risk of future PIH in women whose BP class increased both before 16 (Table 3) and 20 weeks (Table 4) of gestation, even after adjustment for all variables. Thus, JSH 2009 may be a novel, more accurate system for PIH prediction based on a single estimation of maternal BP during pregnancy, particularly if the measurement is taken at early-mid pregnancy, and especially if performed at 20 weeks.

In a previous report, Duckitt et al. ${ }^{16}$ conducted a meta-analysis to evaluate patient characteristics recorded at antenatal booking as risk factors of PIH. These included age, body mass index, nulliparity, previous history of PIH and diabetes mellitus, multiple gestations, family history of PIH and antiphospholipid syndrome. In our study population, age, pre-existing diabetes mellitus and previous history of $\mathrm{PIH}$ were also identified as significant risk factors for PIH.

There were some limitations to our study, including the retrospective design allowing the possibility of some bias and the small size of the study population.

In conclusion, the JSH 2009 classification may be used early in pregnancy to identify women at risk of PIH even in those with optimal or normal BPs. A shift in BP class at 20 weeks of gestation is predictive of subsequent PIH development. JSH 2009 has potential widespread clinical application.

\section{CONFLICT OF INTEREST}

The authors declare no conflict of interest.

\section{ACKNOWLEDGEMENTS}

We wish to thank the women who participated in the T-CHILD study, and Drs H Saito, S Aizawa and R Horikawa, the principal members of the T-CHILD study. We also appreciate with Ms S Saito, Ms C Matsuzawa for management of this cohort data. This study was supported in part by Health and Labour Sciences Research Grants from the Ministry of Health, Labour, and Welfare of Japan (No 09158522). This study was also supported by the Grant of National Center for Child Health and Development (20A-1).
1 Rao AK, Cheng YW, Caughey AB. Perinatal complications among different AsianAmerican subgroups. Am J Obstet Gynecol 2006; 194: e39-e41.

2 Geographic variation in the incidence of hypertension in pregnancy. World Health Organization International Collaborative Study of Hypertensive Disorders of Pregnancy. Am J Obstet Gynecol 1988; 158: 80-83.

3 Cunningham FG, Leveno KJ, Bloom SL, Hauth JC, Rouse DJ, Spong CY. Williams Obstetrics, 23rd edn. McGraw-Hill, New York, NY, 2009, pp. 706.

4 Schroeder BM. ACOG practice bulletin on diagnosing and managing preeclampsia and eclampsia. American College of Obstetricians and Gynecologists. Am Fam Physician 2002; 66: 330-331.

5 Ohkuchi A, Iwasaki R, Suzuki H, Hirashima C, Takahashi K, Usui R, Matsubara S, Minakami $H$, Suzuki M. Normal and high-normal blood pressures, but not body mass index, are risk factors for the subsequent occurrence of both preeclampsia and gestational hypertension: a retrospective cohort study. Hypertens Res 2006; 29: 161-167.

6 Irgens HU, Reisaeter L, Irgens LM, Lie RT. Long term mortality of mothers and fathers after pre-eclampsia: population based cohort study. BMJ 2001; 323: 1213-1217.

7 Norden Lindeberg S, Hanson U. Hypertension and factors associated with metabolic syndrome at follow-up at 15 years in women with hypertensive disease during first pregnancy. Hypertens Pregnancy 2000; 19: 191-198.

8 Wolf M, Hubel CA, Lam C, Sampson M, Ecker JL, Ness RB, Rajakumar A, Daftary A, Shakir AS, Seely EW, Roberts JM, Sukhatme VP, Karumanchi SA, Thadhani R. Preeclampsia and future cardiovascular disease: potential role of altered angiogenesis and insulin resistance. J Clin Endocrinol Metab 2004; 89: 6239-6243.

9 Arnadottir GA, Geirsson RT, Arngrimsson R, Jonsdottir LS, Olafsson O. Cardiovascular death in women who had hypertension in pregnancy: a case-control study. BJOG 2005; 112: 286-292.

10 Vikse BE, Irgens LM, Leivestad T, Skjaerven R, Iversen BM. Preeclampsia and the risk of end-stage renal disease. 2008; 359: 800-809.

11 Aukes AM, de Groot JC, Aarnoudse JG, Zeeman GG. Brain lesions several years after eclampsia. Am J Obstet Gynecol 2009; 200: 504 e1-504 e15.

12 Bellamy L, Casas JP, Hingorani AD, Williams DJ. Pre-eclampsia and risk of cardiovascular disease and cancer in later life: systematic review and meta-analysis. BMJ 2007; 335: 974.

13 Metoki H, Ohkubo T, Watanabe Y, Nishimura M, Sato Y, Kawaguchi M, Hara A, Hirose T, Obara T, Asayama K, Kikuya M, Yagihashi K, Matsubara Y, Okamura K, Mori S, Suzuki $\mathrm{M}$, Imai Y. Seasonal trends of blood pressure during pregnancy in Japan: the babies and their parents' Iongitudinal observation in Suzuki Memorial Hospital in Intrauterine Period Study. J Hypertens 2008; 26: 2406-2413.

14 Denolle T, Daniel JC, Calvez C, Ottavioli JN, Esnault V, Herpin D. Home blood pressure during normal pregnancy. Am J Hypertens 2005; 18(9 Part 1): 1178-1180.

15 Poon LC, Kametas NA, Pandeva I, Valencia C, Nicolaides KH. Mean arterial pressure at $11(+0)$ to $13(+6)$ weeks in the prediction of preeclampsia. Hypertension 2008; 51: 1027-1033.

16 Duckitt K, Harrington D. Risk factors for pre-eclampsia at antenatal booking: systematic review of controlled studies. BMJ 2005; 330: 565.

17 Paynter NP, Cook NR, Everett BM, Sesso HD, Buring JE, Ridker PM. Prediction of incident hypertension risk in women with currently normal blood pressure. Am J Med 2009; 122: 464-471.

18 Dekker GA, Sibai BM. Early detection of preeclampsia. Am J Obstet Gynecol 1991; 165: $160-172$.

19 Chesley LC, Sibai BM. Blood pressure in the midtrimester and future eclampsia. Am J Obstet Gynecol 1987; 157: 1258-1261.

20 Hermida RC, Ayala DE, Iglesias M. Predictable blood pressure variability in healthy and complicated pregnancies. Hypertension 2001; 38(3 Part 2): 736-741.

21 Silva LM, Steegers EA, Burdorf A, Jaddoe VW, Arends LR, Hofman A, Mackenbach JP, Raat $H$. No midpregnancy fall in diastolic blood pressure in women with a low educational level: the Generation R Study. Hypertension 2008; 52: 645-651.

22 Ogihara T, Kikuchi K, Matsuoka H, Fujita T, Higaki J, Horiuchi M, Imai Y, Imaizumi T, Ito S, Iwao H, Kario K, Kawano Y, Kim-Mitsuyama S, Kimura G, Matsubara H, Matsuura H, Naruse M, Saito I, Shimada K, Shimamoto K, Suzuki H, Takishita S, Tanahashi N, Tsuchihashi T, Uchiyama M, Ueda S, Ueshima H, Umemura S, Ishimitsu T, Rakugi H. The Japanese Society of Hypertension guidelines for the management of hypertension (JSH 2009). Hypertens Res 2009; 32: 3-107.

23 Japan Society for study of HYPERTENSION IN PREGNANCY. Guideline 2009 for Care and Treatment of Hypertension in Pregnancy: MEDICAL VIEW 2009 pp. 17. 